\title{
Effect of chemical and biological elicitors on antioxidant potential of Ocimum sanctum
}

\author{
Research Article
}

\section{Shweta Sharma1, Ashika Chourasia², Varnika Kaushik², Gargi Nandi², Joshna Bhatia², Rama Sisodia ${ }^{3 *}$}

1. Assistant Professor, 2. B.Sc Life Sciences and Project fellows, 3. Associate Professor, Department of Botany, Maitreyi College, University of Delhi, New Delhi.

\begin{abstract}
Medicinal plants are a known source of antioxidants and are used for the prevention and treatment of diseases. Exogenous application of elicitors can be used to improve the antioxidant profiles of medicinal plants enhancing their therapeutic potential. Present study aimed to study the effect of elicitors such as proline, salicylic acid and a plant growth promoting rhizobacteria- Azospirillum on antioxidant potential of medicinal plant - Ocimum sanctum. Semi-quantitative assay- thin layer chromatography (TLC), and quantitative assays such as DPPH (2,2Diphenyl-1-picrylhydrazyl) for free radical scavenging activity, total phenolic content and antioxidant responsive enzymes SOD (superoxide dismutase) and CAT (catalase) activities were used for the assessment based on standard protocols. Growth changes like number of leaves, root length, shoot length, total plant height, fresh weight and dry weight observed in response to the treatments given. Exogenous application of proline, salicylic acid and Azospirillum enhanced growth and overall antioxidant content of treated plants. Proline showed higher elicitation with high phenolic content (47.66 GAE/gm. wt.) and number of distinct bands (18) in TLC. The DPPH assay also showed higher free radical scavenging potential $(70.32 \%$ reduction) of proline treated plants. Enhanced activity of antioxidative enzymes CAT and SOD was also observed in all the treated plants. The study confirms the effectivity of using these elicitors for enhancing antioxidant potential of medicinal plants.
\end{abstract}

Key Words: Ocimum sanctum, Proline, Salicylic acid, Azospirillum, Antioxidant.

\section{Introduction}

Ocimum sanctum, commonly called as basil (tulsi), is a potent phytomedicine belonging to family Labiate which has been widely used for the prevention and cure of a multitude of ailments in the Indian traditional system of medicine (Ayurveda) since ages (1). The plant is valued as a rich source of antioxidants (2). Major antioxidants that occur naturally in Ocimum are polyphenols, tannins, saponins and flavonoids $(3,4)$. Production of these antioxidants can be enhanced by application of certain compounds termed as elicitors (5). In the present investigation known elicitors of antioxidants in plants - proline, salicylic acid and Azospirillum were exogenously applied on $O$. sanctum plants and their effect assessed. Proline is a proteinogenic amino acid, highly beneficial for plants in various aspects. It protects plants under stress by acting as an excellent osmolyte, maintaining membrane integrity,

\section{* Corresponding Author:}

\section{Rama Sisodia}

Department of Botany,

Maitreyi College,

University of Delhi,

New Delhi- 110021. India

Email Id: rsisodia@maitreyi.du.ac.in stabilizing enzymes and majorly by acting as a ROS scavenger (antioxidant) (6). As an osmolyte, proline help plants to mitigate water stress and balance turgor pressure $(7,8)$. Exogenous application of proline in plants is known to increase activity of antioxidant enzymes such as catalase (CAT), peroxidase (POX), and superoxide dismutase (SOD) (9). Salicylic acid, is a phenolic phytohormone that confers abiotic and biotic stress tolerance in plants (10). Its exogenous foliar application has been reported to improve phenolic and flavonoid compounds $(11,12)$. Exogenous application of salicylic acid is known to modulate activities of oxidant enzyme in plants under stress (13). Azospirillum is a known Plant Growth Promoting Rhizobacteria (PGPR), which colonizes roots of a wide range of plants, and is known to promote plant growth as well as alleviate effects of stress in plants. It is also capable of inducing biosynthesis of antioxidant enzymes such as CAT and SOD in plants, which not only reduce ROS toxicity but also make use of them as signal transducers for growth, development, and various cellular response $(14,15)$. The present study was aimed to assess the effect of exogenous application of proline, salicylic acid and Azospirillum on growth and antioxidant activity of $O$. sanctum. 


\section{Material and methods}

\section{Growth and Treatment of Plants}

Plants of $O$. sanctum were grown in the Maitreyi College botanical garden. The plants were authenticated by Dr Monika Heikrujam, Maitreyi College, Department of Botany, University of Delhi. One month old plants (in triplicates) were treated for 3 weeks at regular intervals of 4 days. Foliar mode of application for proline $(5 \mathrm{mM})$ and salicylic acid $(1 \mathrm{mM})$ and soil application for Azospirillum $(40 \mathrm{gm} / \mathrm{L})$ was used for the treatment. Growth changes throughout the period were recorded for each plant.

\section{Extract preparation}

The plant materials were air-dried for $48 \mathrm{hrs}$. The completely dried material was crushed into a fine powder using mortar and pestle. Crude extracts were prepared by dissolving the powder in methanol. Further dilutions were made based on respective protocols.

\section{Preparation of Solutions}

- Proline- Proline powder was used to make $25 \mathrm{~mL}$ of its $100 \mathrm{mM}$ stock solution. Further, $500 \mathrm{~mL}$ of $5 \mathrm{mM}$ working proline solution was prepared using the stock.

- Salicylic Acid- Salicylic acid and ethanol were used to make $50 \mathrm{~mL}$ of its $100 \mathrm{mM}$ stock solution. The stock was diluted to make $500 \mathrm{~mL}$ of its $1 \mathrm{mM}$ working solution.

- Azospirillum- The solution was prepared using 40g of Azospirillum biofertilizer and 50g of jaggery dissolved in $1 \mathrm{~L}$ distilled water.

\section{Thin layer chromatography (TLC)}

TLC was performed with methanolic extracts of control and treated samples to determine the number of different phenolic compounds present in Ocimum. For each sample, the TLC plate was loaded with extract using a fine capillary tube and was placed gently in a presaturated TLC jar containing the mobile phase. Once the mobile phase reached $2 / 3$ of its total length, the TLC plates were taken out and the height of the solvent front was marked. The plate was dried and the sample spots were observed under visible light. Toluene and acetone in the 9:1 ratio were used as the mobile phase for performing TLC.

\section{DPPH Free Radical Scavenging Assay}

The assay is based on colour change between oxidised and reduced form of DPPH (2,2-Diphenyl-1picryl hydrazyl) (16). The degree of discoloration indicates the scavenging potential of the antioxidant compounds or extracts in terms of hydrogen donating ability. Dilutions of working concentrations of extract were prepared and $50 \mu \mathrm{l}$ of each concentration was added to $1950 \mu \mathrm{l}$ of methanol and $2 \mathrm{ml}$ of DPPH $(0.1 \mathrm{mM})$. The color change was observed by measuring absorbance at $517 \mathrm{~nm}$. The percentage inhibition of the DPPH radical by the samples was calculated using the following equation:

$$
\% \text { inhibion }=\frac{\left(\mathrm{A}_{0}-\mathrm{A}_{1}\right)}{\mathrm{A}_{0}} \times 100
$$

Where, $\mathrm{A}_{0}$ is the absorbance of the control sample and $A_{1}$ is the absorbance of the test sample.

\section{Total Phenolic Content (TPC)}

The Folin-Ciocalteu reagent (FCR), a mixture of phosphomolybdate and phosphotungstate was used. FCR is extremely light-sensitive and initially, yellow in colour. Under alkaline conditions, the phenolic compounds reduce FCR to give blue colour. This forms the basis of the determination of total phenolics (17). Alkaline conditions are provided using $20 \% \mathrm{Na}_{2} \mathrm{CO}_{3}$, which ease the formation of phenolate ions from the phenols present in the sample.

FCR (oxidised)
(Yellow) $\begin{gathered}\text { alkaline } \\ \text { (Blue) }\end{gathered}$

Absorbance was recorded at $750 \mathrm{~nm}$ spectrophotometrically. $1 \mathrm{ml}$ of sample was mixed with $5 \mathrm{ml}$ distilled water and $0.5 \mathrm{ml} \mathrm{FCR}$ followed by $1.5 \mathrm{ml}$ of $20 \% \mathrm{Na}_{2} \mathrm{CO}_{3}$ after 5 minutes. The tubes were vortexed and incubated in dark for 20 minutes for colour development. Absorbance was measured at 760 $\mathrm{nm}$ and TPC was expressed in terms of gallic acid equivalent, GAE/gm dry weight).

\section{CAT (Catalase) assay}

0.1 gram of fresh leaf tissue of each sample was separately homogenized in $1 \mathrm{ml}$ of extraction buffer in refrigerated mortar and pestle placed in ice bath. Homogenized material was transferred into microcentrifuge tube and centrifuged at $5000 \mathrm{rpm}$ for 20 minutes and the supernatant was collected (18). Bradford assay (19) was used to determine protein concentration. $150 \mathrm{ug} / \mathrm{ul}$ of each protein extract was added in $1 \mathrm{ml}$ of reaction buffer in separate test tubes. This was followed by addition of $0.5 \mathrm{ml}$ hydrogen peroxide. After 1 minute, $1 \mathrm{ml}$ of $1: 3$ dichromate mixture in each sample. As blank, $2 \mathrm{ml}$ each of buffer and dichromate mixture were used and $1 \mathrm{ml}$ of buffer and $0.5 \mathrm{ml}$ of hydrogen peroxide were used as control. All the samples were heated at $80^{\circ} \mathrm{C}$ for 10 minutes. Samples were allowed to cool and absorbance of each sample was measured at $570 \mathrm{~nm}$. CAT activity was calculated as:

$$
\text { CAT activity }=\frac{\text { Control OD }- \text { absorbance } / 9.2059}{\text { Incubation } \times \text { Volume of Enzyme } \times \text { Protein Concentration }}
$$

\section{SOD (Superoxidase dismutase) assay}

0.1 gram of fresh leaf tissue of each sample was separately homogenized in $1 \mathrm{ml}$ of extraction buffer in refrigerated mortar and pestle placed in ice bath. Homogenized material was transferred into microcentrifuge tube and centrifuged at $5000 \mathrm{rpm}$ for 20 minutes and the supernatant was collected. Bradford assay was used to quantitate the protein and $100 \mathrm{ug} / \mathrm{ul}$ of each protein sample was added in $3 \mathrm{ml}$ of reaction buffer in separate test tubes. All the samples were irradiated under the lamp for 15 minutes. Absorbance of each sample was noted at $560 \mathrm{~nm}$ after 15 minutes. Absorbance was measured spectrophotometrically at $560 \mathrm{~nm}$ and percent inhibition of NBT reduction by SOD was calculated (20).

$\%$ Inhibition of NBT reduction by SOD $=\frac{\text { Absorbance control }- \text { Absorbance sample }}{\text { Absorbance control }} \times 100$ 


\section{Results and Discussion}

Growth of treated and control plants of $O$. sanctum in terms of change in number of leaves and shoot was recorded after 4 weeks of treatment. The plants were uprooted and growth parameters including root length, total plant height, fresh weight and dry weight were considered to determine the overall growth of treated plants with respect to control (Fig.1 A-D). The overall plant growth analysis revealed that the exogenous application of proline, salicylic acid and Azospirillum resulted in overall better growth of plants with respect to control in terms all the growth parameters (Fig.2, 3).

Fig. 1: Control and treated plants of $O$. sanctum- A:

Control plant, B: Salicylic acid treated plant, C: Azospirillum treated plant and D: Proline treated plant.

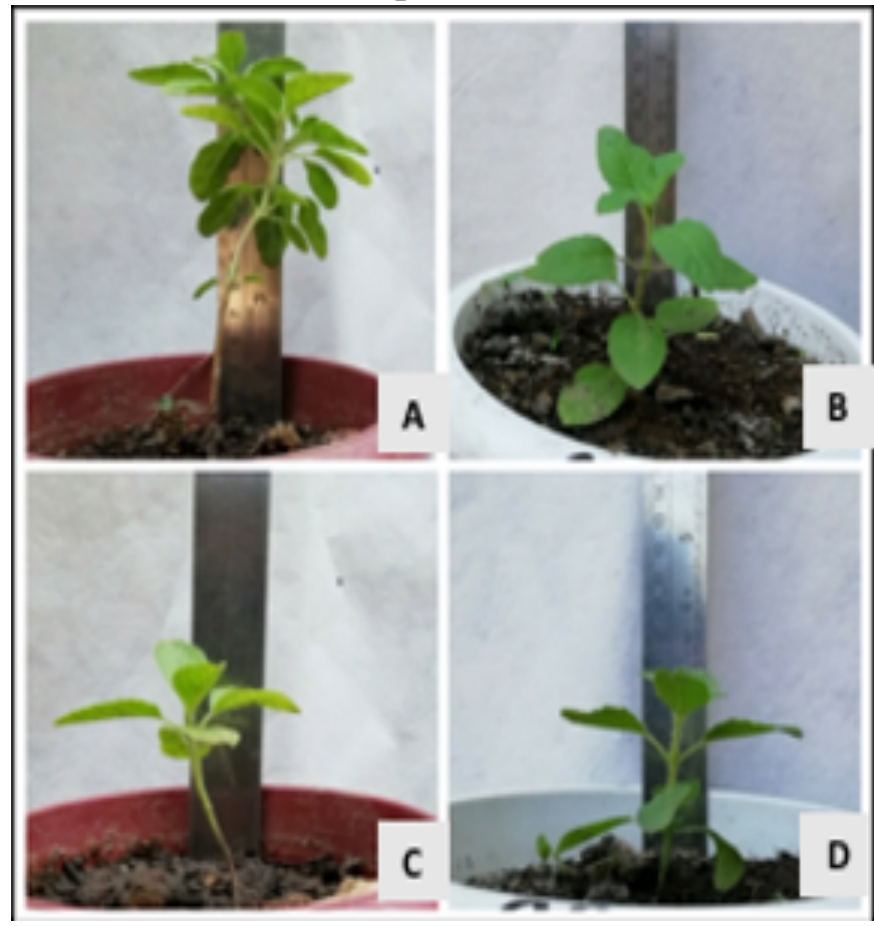

Fig. 2: Comparison of plant growth in control and treated plants of $O$. sanctum.

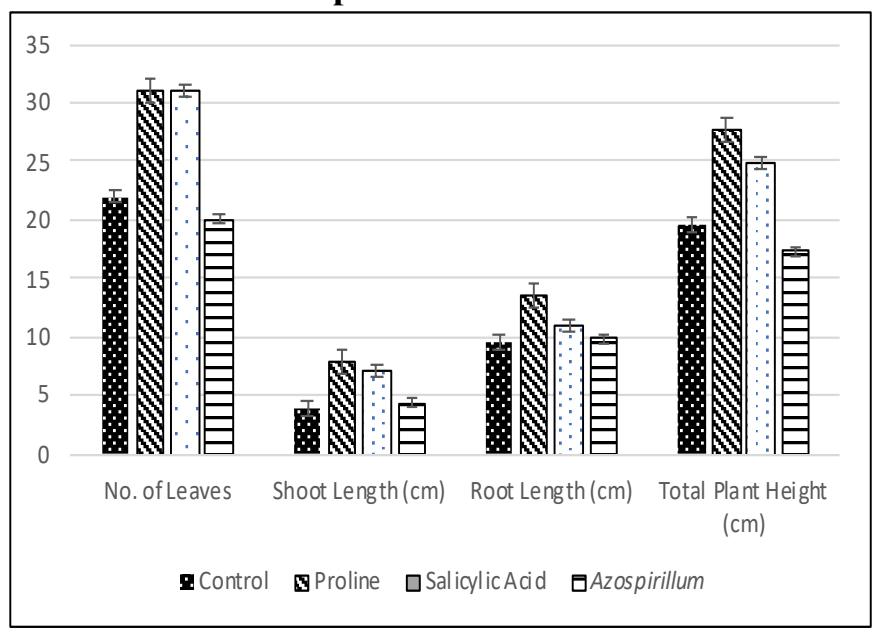

Fig. 3: Comparison of fresh and dry weight in control and treated plants of $O$. sanctum

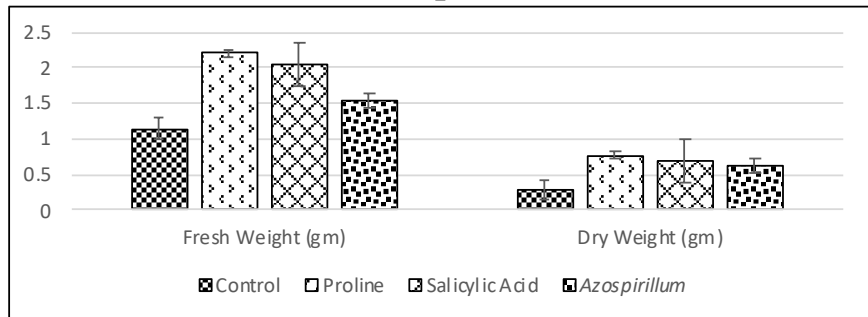

Thin layer chromatography performed to determine the phenolic compounds in control and treated plants of $O$. sanctum showed maximum no. of distinct bands (18) in case of proline treatment (Table 1). Also, the $R_{f}$ values of the several bands in control and treated samples were found to be similar to previously reported values for phytochemicals such as Quercitin (0.38), Eugenol (0.59), Ursolic acid (0.53) $(21,22)$. The exogenous proline application has been reported to increase phenolic acids and flavonoids in plants (23).

Table 1: Comparison of no. of different bands and their $\mathbf{R}_{\mathbf{f}}$ values obtained in TLC for control and treated plants

\begin{tabular}{|c|c|c|c|c|c|}
\hline No. & Treatment & No. of & & $\mathrm{R}_{\mathrm{f}}$ Value & \\
\hline 1 & Control & 16 & 0.042 & 0.085 & 0.128 \\
\hline & & & 0.136 & 0.170 & 0.196 \\
\hline & & & 0.247 & 0.290 & 0.385 \\
\hline & & & 0.418 & 0.461 & 0.641 \\
\hline & & & 0.777 & 0.794 & 0.950 \\
\hline & & & 0.965 & & \\
\hline 2 & Proline & 18 & 0.034 & 0.059 & 0.085 \\
\hline & & & 0.102 & 0.145 & 0.162 \\
\hline & & & 0.213 & 0.273 & 0.358 \\
\hline & & & 0.393 & 0.427 & 0.598 \\
\hline & & & 0.735 & 0.760 & 0.846 \\
\hline & & & 0.888 & 0.974 & 0.991 \\
\hline 3 & Salicylic & 17 & 0.025 & 0.059 & 0.085 \\
\hline & & & 0.125 & 0.170 & 0.195 \\
\hline & & & 0.222 & 0.273 & 0.393 \\
\hline & & & 0.435 & 0.598 & 0.726 \\
\hline & & & 0.756 & 0.846 & 0.888 \\
\hline & & & 0.974 & 0.991 & \\
\hline 4 & Azospirillum & 16 & 0.042 & 0.076 & 0.102 \\
\hline & & & 0.128 & 0.162 & 0.188 \\
\hline & & & 0.239 & 0.282 & 0.367 \\
\hline & & & 0.393 & 0.435 & 0.615 \\
\hline & & & 0.726 & 0.777 & 0.905 \\
\hline & & & 0.982 & & \\
\hline
\end{tabular}

DPPH free radical scavenging assay performed to determine the antioxidant potential in terms of percentage of radical scavenging activity (\% RSA) showed that the exogenous application of proline, salicylic acid and Azospirillum increased the antioxidant potential of treated plants with respect to control. A maximum percentage of radical scavenging was found in the case of proline treated plants $(70.32 \%)$ followed 
Rama Sisodia et.al., Effect of chemical and biological elicitors on antioxidant potential of Ocimum sanctum

by Azospirillum (69.94\%), salicylic acid (32.25\%) and control plants (10.68\%) as shown in Fig. 4.

Fig. 4: Comparison of DPPH radical scavenging activity of control and treated plants

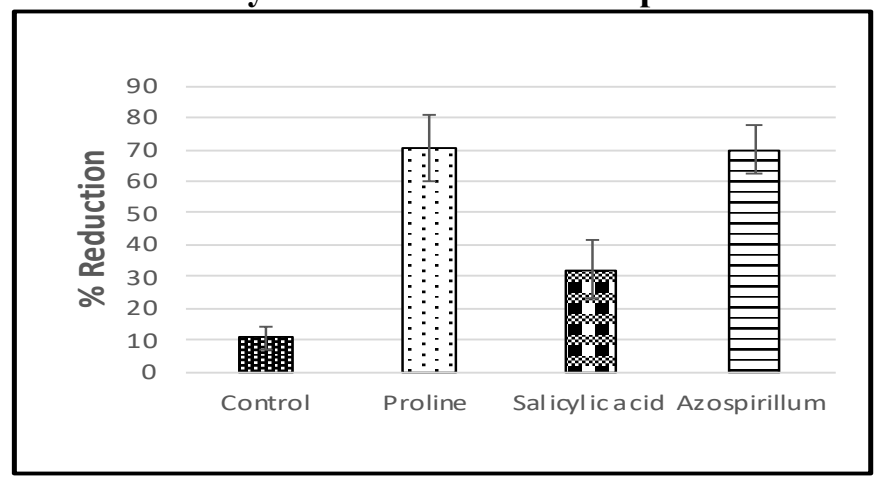

Effect of exogenous application of proline, salicylic acid and Azospirillum on phenolic content of plants was determined by performing total phenolics assay in terms of gallic acid equivalent per gram dry weight (GAE/gm. wt.). The results thus obtained showed that the treatment increased the total phenolic content of plants with respect to control. Proline treated plants showed maximum phenolic content (47.66 GAE/ gm. wt.) followed by salicylic acid (33.63 GAE/gm. wt.), Azospirillum (31.63 GAE/gm. wt.) and control plant (30.39 GAE/gm. wt.) as shown in Fig. 5. Use of elicitors such as salicylic acid and proline are known to increase the synthesis of secondary metabolites such as alkaloids, terpenes and phenolic compounds (24). Exogenous application of salicylic acid triggers the stress signalling mechanisms and the expression of genes encoding enzymes of the phenylpropanoid pathway involved in secondary metabolite synthesis $(25,26)$.

\section{Fig. 5: Comparison of total phenolic content (GAE/} gm. wt.) of control and treated plants

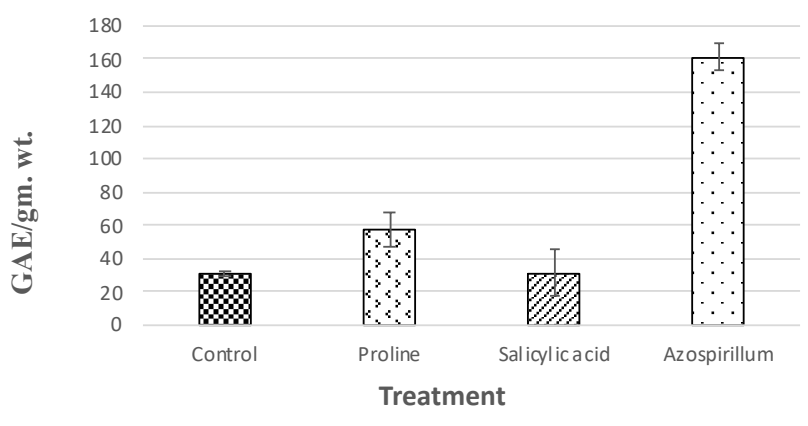

CAT assay was performed to determine the catalase activity in treated plants with respect to control. It was found that the exogenous application of proline, salicylic acid and Azospirillum resulted in increased catalase activity of plants. Salicylic acid treated plants showed maximum catalase activity $(1.18 \mathrm{moles} / \mathrm{min}$. $\mathrm{mg})$ followed by proline $(0.76 \mathrm{moles} / \mathrm{min} . \mathrm{mg})$, Azospirillum (0. 63 moles/min. $\mathrm{mg}$ ) and control $(0.58$ moles/min. mg) as shown in Fig. 6.
Fig. 6. Catalase activity (moles/min. $\mathrm{mg}$ ) of control and treated plants

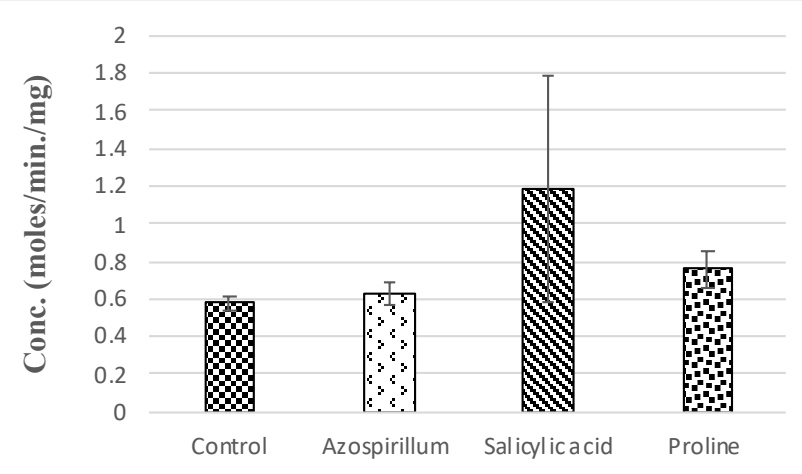

SOD assay was performed to determine the activity of enzyme superoxidase dismutase in treated plants with respect to control. It was found that plants treated with proline, salicylic acid and Azospirillum showed higher SOD activity in comparison to the untreated plants. A maximum SOD activity was observed in the case of proline treated plants $(25.22 \%)$, followed by salicylic acid (16.88\%), Azospirillum $(15.39 \%)$, and control plants $(13.96 \%)$ as shown in Fig. 7. The enzymes SOD and catalase belong to the class of antioxidants that are involved in maintaining the critical cellular redox homeostasis. Exogenous application of elicitors is known to increase the antioxidant enzymes thereby enhancing bioactive profiles of plants $(27,28)$.

Fig. 7. SOD activity (moles/min. mg) of control and treated plants.

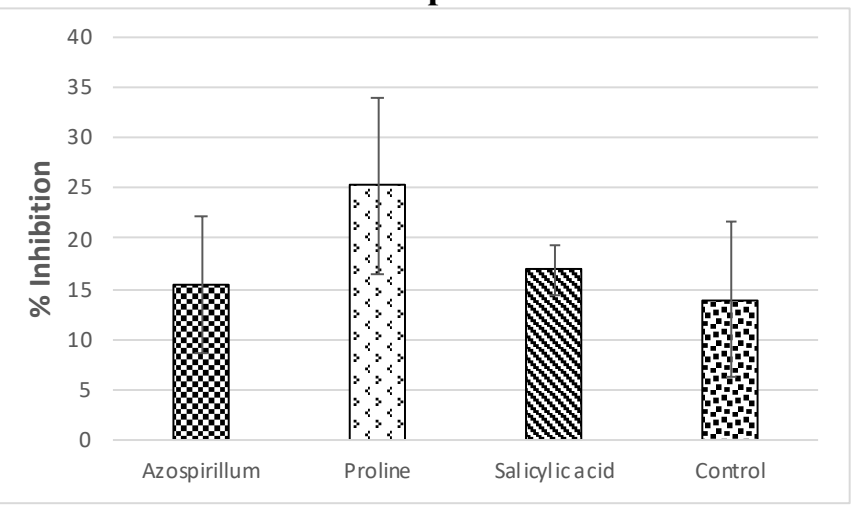

\section{Conclusion}

Based on the experiments performed under the present study, it was concluded that the exogenous application of proline, salicylic acid and Azospirillum was effective in enhancing the antioxidant potential of $O$. sanctum plants. Antioxidants are an important plant resource and a booming market. As more and more people are turning to plant-based medications, it becomes imperative to enhance antioxidants of important medicinal plants to meet the rising demands. Proline, salicylic acid and PGPR-Azospirillum have shown a promising effect in enhancing antioxidants of Ocimum sanctum and similar experiments can be considered to enhance antioxidant activity in other medicinal plants too. 


\section{Acknowledgement}

The research was carried out under the aegis of Summer Internship Program - 2019, Center for Research, Maitreyi College, University of Delhi. The authors gratefully acknowledge the resources and support provided by the Principal and staff of Maitreyi College.

\section{Conflict of interest}

The authors declare no conflict of interest.

\section{References}

1. Cohen M.M. Tulsi - Ocimum sanctum: A herb for all reasons. J. Ayurveda Integr. Med. 2014; 5(4); 251-259.

2. Agarwal K, Singh D.K, Jyotshna J, Ahmad A, Shanker K, Tandon S, Luqman S. Antioxidative potential of two chemically characterized Ocimum (Tulsi) species extracts. Biomedical Research and Therapy. 2017; 4(9); 1574-90.

3. Tewari, D., Sah A. N, Pandey H. K, Meena H. S. A Review on Phytoconstituents of Ocimum (Tulsi). International Journal of Ayurvedic Medicine. 2012; 3(1);1-9.

4. Hakkim F.L, Shankar C.G, Girija S. Chemical composition and antioxidant property of holy basil (Ocimum sanctum L.) leaves, stems, and inflorescence and their in vitro callus cultures. Journal of Agricultural and Food Chemistry. 2007; 55(22); 9109-17.

5. Ferrari S. Biological elicitors of plant secondary metabolites: Mode of action and use in the production of nutraceutics. InBio-Farms for Nutraceuticals 2010 (pp. 152-166). Springer, Boston, MA.

6. Hayat K, Khan J, Khan A, Ullah S, Ali S, Fu Y. Ameliorative Effects of Exogenous Proline on Photosynthetic Attributes, Nutrients Uptake, and Oxidative Stresses under Cadmium in Pigeon Pea (Cajanus cajan L.). Plants. 2021;10(4); 796.

7. Furlan A.L, Bianucci E, Giordano W, Castro S, Becker D.F. Proline metabolic dynamics and implications in drought tolerance of peanut plants. Plant Physiology and Biochemistry. 2020 ; 151; 566-78.

8. Zali A.G, Ehsanzadeh P. Exogenous proline improves osmoregulation, physiological functions, essential oil, and seed yield of fennel. Industrial Crops and Products 2018;111; 133-40.

9. El-Beltagi H.S, Mohamed H.I, Sofy M.R. Role of ascorbic acid, glutathione and proline applied as singly or in sequence combination in improving chickpea plant through physiological change and antioxidant defense under different levels of irrigation intervals. Molecules. 2020; 25(7); 1702.

10. Kumar V, Amomin S. Plant defense against pathogens: the role of salicylic acid. Res. J. Biotechnol. 2018; 13; 97-103

11. Rangel P.P, Perez J.J, Rodriguez S.C, Perez L.S, Hernandez M.F, Amador B.M, Dieguez E.T. Foliar aspiration of salicylic acid improves phenolic and flavonoid compounds, and also the fruit yield in cucumber (Cucumis sativus L). Plants. 2019; 8; 44.

12. Blanch G.P, Jimenez M.C, Castillo M.L. Exogenous salicylic acid improves phenolic content and antioxidant activity in table grapes. Plant Foods for Hum Nutr. 2020;75;177-183

13. Kim Y, Mun B.G, Khan A.L, Waqas M, Kim H.H, Shahzad R, Imran M, Yun B.W, et.al. Regulation of reactive oxygen and nitrogen species by salicylic acid in rice plants under salinity stress conditions. Plos One. 2018;13(3).

14. Fukami J, Cerezini P, Hungria M. Azospirillum: benefits that go far beyond biological nitrogen fixation. AMB Express. 2018; 8(1); 1-2.

15. Bulegon LG, Guimaraes VF and Laureth JC. Azospirillum brasilense affects the antioxidant activity and leaf pigment content of Urochloa ruziziensis under water stress. Pesqui Agropecu Trop. 2016; 46; 343-349.

16. Chang S.T, Wu J.H, Wang S.Y, Kang P.L, Yang N.S, Shyur L.F. Antioxidant activity of extracts from Acacia confusa bark and heartwood. J Agric Food Chem 2001;49: 3420-3424

17. Folin O, Ciocalteu V. On tyrosine and tryptophan determination in proteins. J. Biol. Chem. 1927; 73; 627-650

18. Sinha A. K. Colorimetric assay of catalase. Analytical Biochemistry. 1972; 47(2); 389-94.

19. Bradford, M. M. A rapid and sensitive method for the quantitation of microgram quantities of protein utilizing the principle of protein-dye binding. Analyt. Biochem. 1976; 72; 248-254.

20. Beauchamp C, Fridovich I. Superoxide dismutase: improved assays and an assay applicable to acrylamide gels. Anal. Biochem. 1971; 44; 276-87.

21. Singh J, Gupta SJ, Singh AK. Standardization of Tulsi (Ocimum sanctum Linn.). Int. J. Ayu. Pharm Chem 2015; 4(1); 165-75.

22. Gupta P, Yadav D, Siripurapu K, Palit G, Maurya R. Constituents of Ocimum sanctum with Anti-stress Activity. J. Nat. Prod. 2007;70;1406-1410.

23. Mohammadrezakhani S, Hajilou J, Rezanejad F, Nahandi F. Z. Assessment of exogenous application of proline on antioxidant compound in three Citrus species under low temperature stress. J. Plant Interact. 2019; 14; 347-358.

24. Poorghadir M, Torkashvand AM, Mirjalili SA, Moradi P. Interactions of amino acids (proline and phenylalanine) and biostimulants (salicylic acid and chitosan) on the growth and essential oil components of savory (Satureja hortensis L.). Biocatalysis and Agricultural Biotechnology. 2020; 30; 101815.

25. Gorni PH, Pacheco AC. Growth promotion and elicitor activity of salicylic acid in Achillea millefolium L. African Journal of Biotechnology. 2016 Apr 19; 15(16); 657-65.

26. Pérez MG, Rocha-Guzmán NE, Mercado-Silva E, Loarca-Piña G, Reynoso-Camacho R. Effect of chemical elicitors on peppermint (Mentha piperita) plants and their impact on the metabolite profile and 

antioxidant capacity of resulting infusions. Food Chemistry. 2014; 156; 273-8.

27. Ramakrishna R, Sarkar D, Shetty K. Metabolic stimulation of phenolic biosynthesis and antioxidant enzyme response in dark germinated barley (Hordeum vulgare L.) sprouts using bioprocessed elicitors. Food Science and Biotechnology. 2019; 28(4); 1093-106.
28. El-Esawi MA, Elansary HO, El-Shanhorey NA, Abdel-Hamid AM, Ali HM, Elshikh MS. Salicylic acid-regulated antioxidant mechanisms and gene expression enhance rosemary performance under saline conditions. Frontiers in Physiology. 2017; 8; 716. 